\title{
THE CHOICE OF RATIONAL TECHNOLOGY OF DELIVERY OF GRAIN CARGOES IN THE CONTAINERS IN THE INTERNATIONAL TRAFFIC
}

\author{
Olexiy Pavlenko' ${ }^{1}$, Denis Velykodnyi ${ }^{2}$ \\ ${ }^{1}$ Kharkiv National Automobile and Highway University, Yaroslava Mudrogo street, 25, Kharkov, Ukraine \\ ${ }^{2}$ Motor Transport College of State Higher Educational Establishment «Kryvyi Rih National University», \\ Eduard Fuks street, 26, Kryvyi Rih, Ukraine
}

Received 30 March 2017; accepted 3 May 2017

\begin{abstract}
The analysis of delivery technology of grain cargoes in the containers in the international traffic have enabled to offer three alternative technological schemes of delivery of grain cargoes in the international traffic: the first scheme is with the use of rail transport (grain cars) to deliver grain to the port of departure, the second scheme is with the use of road transport (bulk grain lorries) to deliver grain to the port of departure, the third scheme is with the use of the containers and carriages to deliver grain to the port of departure. The model describing the factors that affect the system is built: input parameters (the shipment volume, the distance of transportation); output parameters - the total expenses on grain delivery from the elevator of the shipper to the shipper, taking into account external factors: the specific time of loading, unloading, average technical speed of transportation, downtime at the customs point. The full-factorial plan of the experiment has been developed which consists of 9 series of experiments. Based on the regression analysis of the experimental results the regression model is determined in a linear form with non-zero coefficient where each factor indicates the degree of influence of the relevant factor on the effective rate. The results of the effect determination on the change of the distance of cargo delivery for volume shipment of 200 tons have got the greatest effect.
\end{abstract}

Keywords: grain cargoes, international traffic, container, vehicle, carriage, port, regression model.

\section{Introduction}

In the modern conditions, in the market of transportation of grain cargoes in the containers, there is a perspective of their development because every year the number of such orders is increasing to the address of transport and freight forwarding companies (Ellram and Cooper, 1990; Schepler et al., 2017). The authors focus on the development of multimodal transportation involving railway transport, road and marine type of transport in the scientific works in the sphere of cargo shipping in the containers, thus it is determined that railroad transport carries out the transportation of the grain cargoes in the conditions of critical depreciation of the main means and increasing competition from the side of other types of transport (Collins et al., 2017; Zheng and Park, 2016; Sayareh

\footnotetext{
${ }^{1}$ Corresponding author: email ttpov@ukr.net
} 
et al., 2016; Wisner and Tan, 2000; Boyson et al., 1999; Bowersox et al., 1986; Song and Dong, 2012; Zhivitskaya, 2014; Chen and Yan, 2012; Pavlenko et al., 2014; Velikodnyi, 2015). The analysis of the practical experience of the organization of grain cargoes delivery in the containers in international traffic has shown that many companies offer services on this type of activity, using different technical means to simplify the process of loading and unloading and transportation of grain cargoes (Kozachenko et al., 2011; Cherevychnyi, 2016). The analysis of the current state of the matter of shipment grain cargoes from Ukraine has shown that our country has a powerful export port capacity. In addition, two leaders in storage and transshipment of grain cargoes have been specified, Odessa and «Chernomorsk» sea trade port. It has been found out that delivery of grain cargoes to the seaport is used by bulk grain lorries, carriages, containers. The held analysis has revealed the problem of delivery organization of grain cargoes in the international traffic - the choice of rational technology of delivery. The aim of this development is the definition of rational technology of delivery of grain cargoes in the containers in the international traffic. The object of the research is the process of delivery of grain cargoes in the containers in the international traffic.

\section{The Development of a Model of the Definition Rational Technology of the Delivery of Grain Cargoes in Containers}

Modern international conditions which Ukraine strives demand more attention in the sphere of logistics cargo transportation, the rapid growth and development. The efficiency and the quality of cargo transportation significantly depends on the optimization of the process of work coordination of different types of transport, rational distribution between traffic volumes, timely formation of the necessary management decisions. First, it is necessary to pay special attention to the important indicator of transport process - the cost of transportation implementation.

Three alternative technological schemes of delivery of grain cargoes in the containers in the international traffic have been proposed.

The first scheme is with the use railroad transport (grain cars) to deliver the grain to the port of departure «loading of the rail car at the elevator - delivery to the port or the external terminal - reloading into the container - delivery of the container by the sea lines - delivery to the end user».

Scheme 1. This scheme has some significant moments that influence the process, according to the statistics at this scheme technical losses make up from 5\% to $7 \%$ of the total turnover of the product; the impossibility of forecasting the timing of a process; additional costs on certification and customs clearance.

The second scheme is with the use of road transport (bulk grain lorries) for the grain delivery to the port of departure «loading of the bulk grin lorry on the elevator delivery to the port or the external terminal - reloading of the container - delivery of the container by the sea lines - delivery to the end user».

Scheme 2. This option has several significant factors affecting the process: the lack of delivery schedule and respectively planning of the shipments; non-conformity of the quality of goods which are transported; lack of laboratories at cargo complexes; technical losses of $3 \%$ to $5 \%$. 
Scheme 3. The third scheme is with the use the containers and railcars for grain deliver to the port of departure «supply of empty containers for loading on the elevator by railroad - loading on the elevator - the return of the loaded containers to the port - delivery of the container by the sea line - delivery to the end user». The main advantages of the third option: the grain goes through qualitative selection; no overload, except loading on the elevator; low cost price of export certification and customs clearance; minimal loss of cargo $-0.5 \%$.

The most wide-spread are the following models: physical, mathematical, simulation, axiomatic that are used by the main parts of the system and developed in the form of technological schemes or levels for common idea about the process and the result of its operation which are divided in its turn into deterministic and stochastic (Naumov et al., 2015).

The most perspective to describe the process of cargo transportation on transport and technological schemes is the use of mathematical modeling. When designing and developing new models a number of difficulties appear the main cause of which is not only in a large number of items which are included in the projected system but in the complication of causation ties in the complex of interacting components.

Since transport processes are complex systems of interacting elements, so it is appropriate for their modeling techniques to apply the systems analysis which essence is to identify the connection between the components of the object of research and the impact of each of them on the efficiency of the system as a whole.
Using the aparatus of the set theory the technological process is considered on the basis of the model $M_{T P}$ as the combination of the following components described in eq (1):

$$
M_{T P}=\{\{X\},\{Y\},\{Z\},\{E\},\{L S\}\},
$$

where $\{X\}$ - the input impacts that can be changed in the process of taking decision as for the management of transport process;

$\{Y\}$ - criteria of effectiveness of the transport process;

$\{Z\}$ - environmental effects that cannot be changed during making management decision but should be taken into account herewith;

$\{E\}$ - components of the transport process; $\{L S\}$ - connections between the elements of the transport process.

This model describes: all the elements of the system (warehouse); all communications of the systems: internal (structure), external (inputs, outputs); boundaries of the system; parameters of the environment; parameters of the internal environment.

The effects of the environment that cannot be changed during making the management decision but should be taken into account herewith $\{X\}$ :

$q$ - shipment volume, t;

$L$ - distance of transportation on the territory of Ukraine, $\mathrm{km}$.

Performance measures of the transport process $\{Y\}$ : 
$\sum C$ - the total cost of shipping grain, US\$;

The input impacts that can be changed in the process of making decision as for the transport process management $\{Z\}$ :

$t_{\text {load.1t }}-$ specific load time, $\mathrm{h} / \mathrm{t}$;

$t_{\text {unload } .1 t}-$ specific time of unloading. $\mathrm{h} / \mathrm{t}$;

$V_{t}^{i}$ - the average technical speed of transportation $\mathrm{km} / \mathrm{h}$.

$\grave{O}_{\text {cus }}$ - downtime at the customs point, h.;

The constituent elements of the transport process $\{E\}$ :

$C_{1}$ - the cost on downloading of a railway wagon, bulk grin lorry, container on the elevator for the relevant schemes US\$;

$C_{2}$ - the costs of transporting grain to the terminal (port), US\$;

$C_{3}$ - the cost on grain overload into the container and the container to the terminal (port) according to the schemes US\$;

$C_{4}$ - the cost on loading the container on the ship, US\$;

$C_{5}$ - the cost on moving the ship with the containers, US\$;

$C_{6}$ - the cost on unloading the ship in the port of destination, US\$;
$\mathrm{C}_{7}$ - the cost on delivery of the container to the consignee, US\$;

$\mathrm{C}_{8}$ - the cost on unloading the container, US\$.

Relations between the elements of the transport process $\{L S\}$ :

- The shipment volume affects the costs of work of loading and unloading of the grain cargoes, the cost of serving and preparation of the vehicle (vehicle), including container, the costs of loading and unloading of the containers at the ports of departure and destination;

- Distances of the transportation affect the costs of transportation from the elevator to the terminal (port), the cost of moving the containers from the ship with the containers, as well as the cost on container delivery to the consignee;

- Respectively the specific time of loading and specific time of unloading affect the cost on loading-unloading works;

- Average technical transport speed affects the costs of transportation;

- Downtime at the customs point affects the cost of simple load at the customs point;

- The cost on implementation each technological operation affects the total cost on delivery of the grain from the elevator to the consignee.

All the system elements and connections between them are presented in the form of the model «white box» in the Figure 1. 


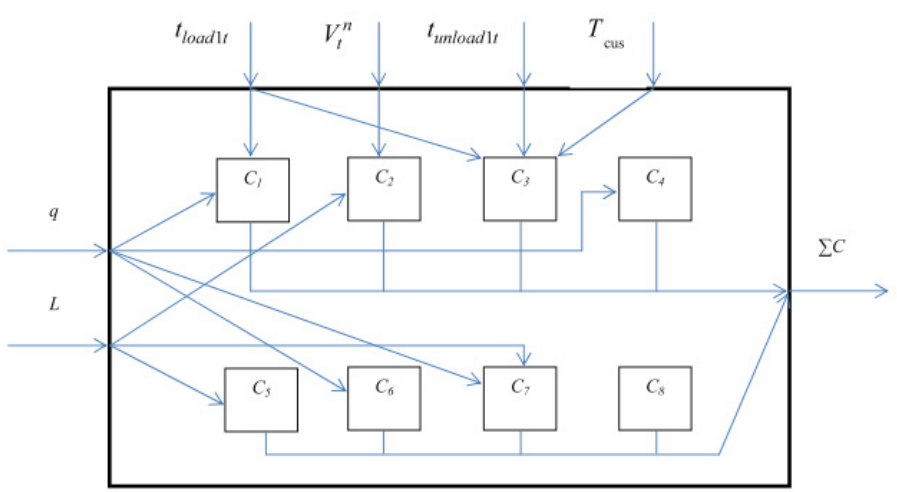

Fig. 1.

Cybernetic Model of «White Box»

The function is the total cost on grain delivery which must aim to the minimum, eq (2):

Under restrictions presented in eqs (3):

$$
\left\{\begin{array}{l}
20 \leq q \leq 200 \mathrm{t} . \\
150 \leq L \leq 1000 \mathrm{~km} . \\
0,15 \leq t_{\text {load } .1 t} \leq 0,28 \mathrm{~h} / \mathrm{t} . \\
0,19 \leq t_{\text {unload } .1 t} \leq 0,37 \mathrm{~h} / \mathrm{t} . \\
1 \leq O_{\text {cus }} \leq 3 \mathrm{~h} . \\
5 \leq V_{t}^{i} \leq 50 \mathrm{~km} / \mathrm{h}
\end{array}\right.
$$

$\sum C\left(q, L, t_{\text {load.1t }}, t_{\text {unload.1t }}, \grave{O}_{\text {cus }}, V_{t}^{i}\right) \rightarrow \min$.

$$
C_{1}=C_{\text {prep }}+C_{\text {down }}+C_{\text {paper }},
$$

where $C_{\text {prep }}$ - the cost on preparing the vehicle including a container before the loading, US\$;

$C_{\text {down }}$ - the cost on loading the grain into the vehicle, including container, US\$;

$C_{\text {paper }}$ - the cost of paperwork and special certificates, US\$.

The cost on preparing the container for loading (for Scheme 3) is presented in eq (6):

$C_{\text {prep }}=N_{c} \cdot \tilde{N}_{\text {prep.1c }}$,

The total costs on grain cargo delivery are where $N_{c}$ - the number of the containers, calculated according to the equation (4): units;

$\sum C=C_{1}+C_{2}+C_{3}+C_{4}+C_{5}+C_{6}+C_{7}+C_{8}$,

$\tilde{N}_{\text {prep.lc }}$ - the rate on the preparation of one container for loading, US\$ / unit.

The number of containers, eq (7):

The costs on loading the grain on the elevator, eq (5):
$N_{c}=\frac{q_{n}}{q_{c}}$, 
where $q_{c}$ - nominal carrying capacity of the container, $\mathrm{t},\left(q_{c}=20 \mathrm{t}\right)$.

The costs on loading grain, eq (8):

$$
C_{\text {load }}=q \cdot C_{\text {load.1t }} \cdot t_{\text {load } 1 t},
$$

where $C_{\text {load.lt }}$ - the rate for loading 1 ton of cargo in the vehicle, including container, US\$ / h 1 t.

The costs of transporting grain to the terminal (port), eq (9):

$C_{2}=q \cdot C_{\text {trans.1t }} \cdot T_{\text {trans }}$,

where $C_{\text {trans.1t }}$ - the rate for transportation $1 \mathrm{t}$ of cargo in the vehicle, US\$ / $\mathrm{h} \mathrm{t}$.;

$T_{\text {trans }}-$ transportation time, $\mathrm{h}$.

Time of transportation, eq (10):

$T_{\text {trans }}=\frac{L}{\bar{V}_{t}^{i}}$,

where $L$ - distances of transportation, $\mathrm{km}$.

$\bar{V}_{t}^{i}$ - the average technical speed of transportation.

The cost of grain reloading in the container to the terminal (in the port), including reloading of the container for the Scheme 1 and Scheme 2, eq (11):

$C_{3}=C_{\text {unload }}+C_{\text {prep }}^{c}+C_{\text {down }}+C_{\text {cost of stor. }}+C_{\text {cost of down. }}$,

where $C_{\text {unload }}$ - the cost for unloading the grain from the vehicle, including from the container, US\$;

$C_{\text {prep }}^{c}$ - preparing the container for loading, US\$;
$\mathrm{C}_{\text {cost of stor. }}$ - the cost of storage at the terminal (at the port), US\$;

$C_{\text {cost of down. }}$ - the cost of downtime at the customs point, US\$;

For the Scheme 3, eq (12):

$C_{3}=C_{\text {unload }}^{c}+C_{\text {cost of stor. }}+C_{\text {cost of down. }}$,

where $C_{\text {unload }}^{c}$ - the cost on unloading the container from the vehicle, US\$

Costs for unloading the grain from the vehicle, including the container eq (13):

$C_{\text {unload }}=q \cdot C_{\text {unload. } 1 t} \cdot t_{\text {unload } 1 t}$,

where $C_{\text {unload.1t }}$ - the rate on unloading 1 ton of load from the vehicle, including from the container, US\$ / hour. 1t.

The cost on loading the container on the ship, eq (14):

$C_{4}=N_{c} \cdot \tilde{N}_{\text {load.1c }}^{s l}$,

where $\tilde{N}_{\text {load.1c }}^{i \tilde{n}}$ - the rate on loading one container on the ship US\$ / unit.

The cost on moving a ship with the containers, eq (15):

$C_{5}=N_{\hat{e}} \cdot L_{\text {sea }} \cdot C_{\text {trans }}^{s l}$,

where $L_{\text {sea }}$ - distance of transportation of the containers by the sea lines, $\mathrm{km}$.

$C_{\text {trans }}^{s l}$ - the rate on the transportation of one container by the sea line, US\$ / $\mathrm{km}$.

The cost on unloading the ship in the port of destination, eq (16): 


$$
C_{6}=N_{c} \cdot \tilde{N}_{\text {unload.1c }}^{i \tilde{n}},
$$

where $\tilde{N}_{\text {unload.1c }}^{s l}$ - rate on unloading one container from the ship, US\$ / unit.

The costs on delivery of the container to the consignee, eq (17):

$$
C_{7}=C_{\text {load }}^{c}+C_{\text {trans }}+C_{\text {unload }}^{c}
$$

where $C_{\text {load }}^{c}$ - the cost on loading the container on the vehicle at the port of destination, US\$;

$C_{\text {trans }}$ - the cost of transportation of container from the port of destination to the recipient, US\$;

$C_{\text {unload }}^{c}$ - the cost on unloading the container from the vehicle at the port of destination, US\$

The cost on loading the container on the vehicle at the port of destination, eq (18):

$$
C_{\text {load }}^{c}=N_{c} \cdot \tilde{N}_{\text {load }}^{c},
$$

where $\tilde{N}_{\text {load }}^{c}$ - rate on loading the container on the vehicle at the port of destination, US\$ / unit.

The cost of transportation of the container from the port of destination to the recipient, eq (19):

$$
C_{\text {trans }}=N_{c} \cdot \bar{L} \cdot C_{\text {trans }}^{c},
$$

where $\bar{L}$ - the average distance of transportation from the port of the destination to the recipient, $\mathrm{km}$;

$C_{\text {trans }}^{c}$ - the rate on transportation of the containers from the port of the destination to the recipient, US\$ / $\mathrm{km}$.
The costs of unloading the container are calculated similarly using the equation (13).

\section{The Experimental Research on} Selection the Rational Technology of Delivery of Grain Cargoes in the

\section{Containers}

The method that consists of four stages has been chosen to determine the rational transport and technological schemes of delivery of grain cargoes in the containers in the international traffic:

- Determination of alternative delivery schemes of grain cargoes;

- Determination and assessment of input parameters;

- Calculation of total costs;

- The choice of a rational scheme of delivery of grain cargoes.

On solving this problem the following assumptions have been taken:

- The delivery of grain cargoes is carried out in the universal, specially equipped 20-foot containers;

- The volume of shipments varies from 20 to 200 tons;

- The distance of transportation refers to one shipment and varies from 150 to $1000 \mathrm{~km}$;

- First class cargo;

- Grain transportation of the containers is carried out by rail transport;

- Container loading with grain is made at the expense of the carrier;

- The search of the empty containers is carried out by the carrier;

- Shipment of the containers by the sea lines is made from Odessa STP;

- The value of the distance of transportation of the containers by sea 
line is accepted from Odessa STP to the port of Alexandria (Egypt);

- The value of transportation distance from the port of destination to the recipient is taken as the average;
- The level of tariffs is determined as the average in the market of services.

The input parameters at different levels of varying factors are presented in Table 1.

\section{Table 1}

Levels of Varying Factors

\begin{tabular}{|c|c|c|c|}
\hline Parameter & $\begin{array}{c}\text { Minimum } \\
\text { value }\end{array}$ & $\begin{array}{c}\text { Average } \\
\text { value }\end{array}$ & Maximum value \\
\hline Volume of shipment $[\mathrm{t}]$ & 20 & 110 & 200 \\
\hline Distance of transportation $[\mathrm{km}]$ & 150 & 575 & 1000 \\
\hline
\end{tabular}

The minimum, average and maximum values of $q, L$, have been used for the experiment. It is necessary to carry out the generation of random values for these parameters for the experiment. To generate the specific time of loading, specific time of unloading, specific time of unloading the container, downtime at the customs point, the normal distribution law was selected as the average technical speed of transportation. The series number of the experiments is 9 . Since 3 levels of variation have been selected, they are marked as follows: «-» - the $1^{\text {st }}$ variation level (min), «0»- $2^{\text {nd }}$ level (mid), «+» - 3rd level (max). Then all possible combinations of the combinations are entered in the Table 2.

\section{Table 2}

Plan of the Experiment

\begin{tabular}{|c|c|c|}
\hline \multirow{2}{*}{ Series } & \multicolumn{2}{|c|}{ Varying levels of input factors } \\
\cline { 2 - 3 } & $\begin{array}{c}\text { Volume of } \\
\text { shipments }[\mathbf{t}]\end{array}$ & $\begin{array}{c}\text { Transportation } \\
\text { distance }[\mathbf{k m}]\end{array}$ \\
\hline 1 & - & - \\
\hline 2 & 0 & - \\
\hline 3 & + & - \\
\hline 4 & - & 0 \\
\hline 5 & 0 & 0 \\
\hline 6 & + & 0 \\
\hline 7 & - & + \\
\hline 8 & 0 & + \\
\hline 9 & + & + \\
\hline
\end{tabular}

Based on the received values of costs, here are the graphs of costs on the distance of transportation at the volume of shipment
$20,110,200$ tons for the Scheme 1, Scheme 2 and Scheme 3 (Figures 2, 3, 4). 


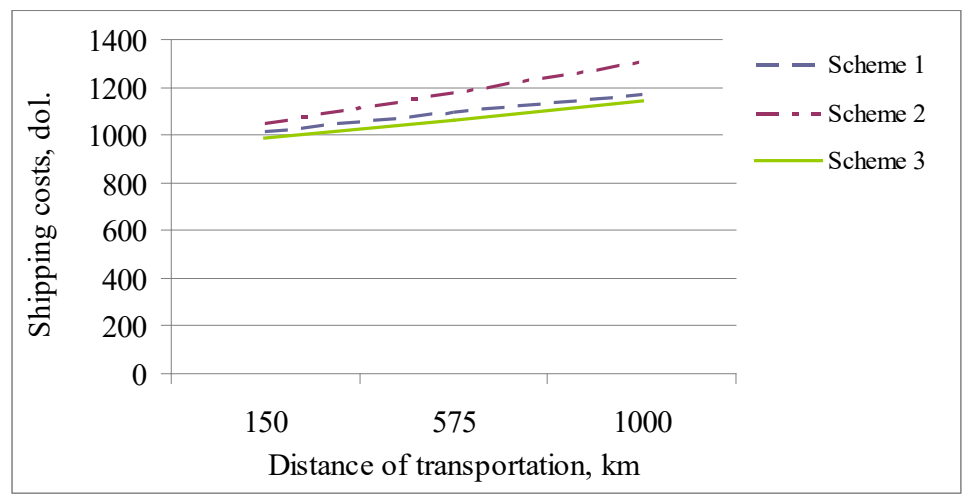

Fig. 2.

Graph of Costs on the Distance of Transportation at the Volume of Shipment 20 tons

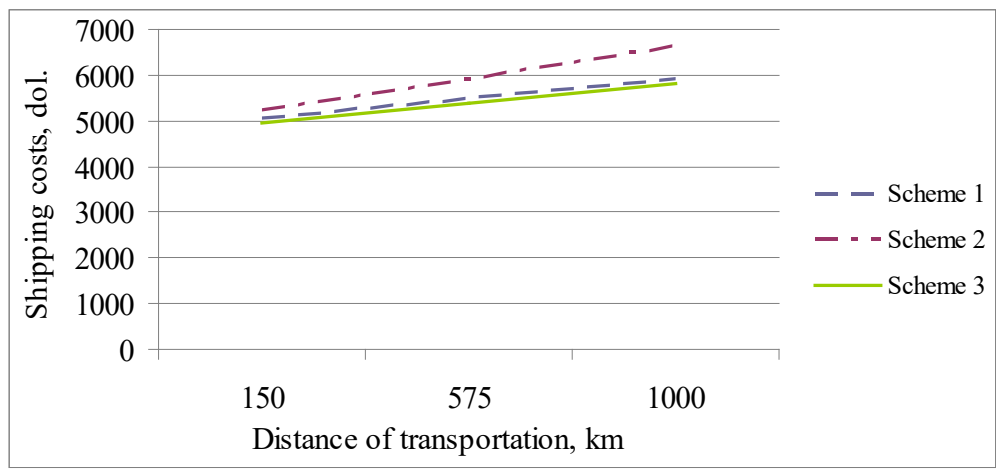

Fig. 3.

Graph of Costs on the Distance of Transportation at the Volume of Shipment of 110 tons

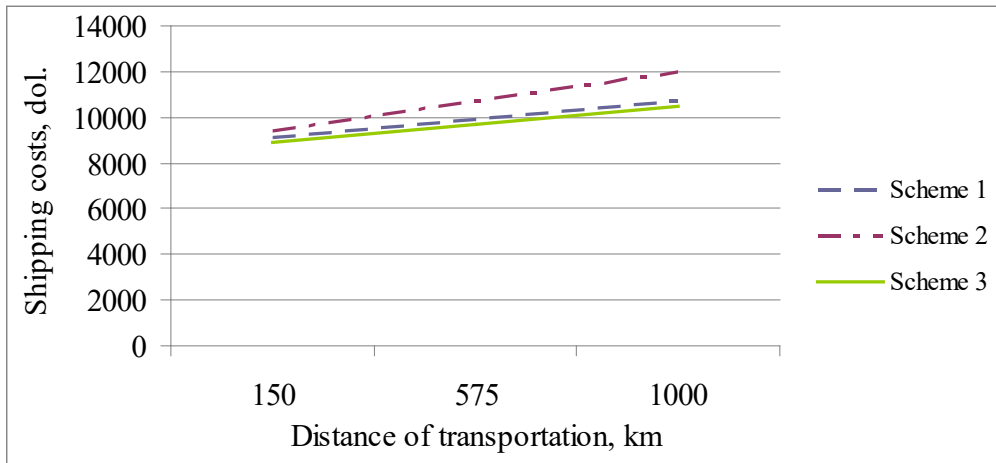

Fig. 4.

Graph of Costs on the Distance of Transportation at the Volume of Shipment of 200 tons 
It is shown from the graphs that on increasing the distance and the volume of shipment the costs increase. Moreover, the costs on using bulk grain lorries (Figure 2) are the greatest comparing with using the rail cars and containers (Figure 1 and Figure 3 ) at any distance and traffic volumes. The scheme 3 was the most profitable, i.e. the use of containers on delivery of the grain cargoes, as it requires minimal costs.

\section{Analysis of the Research Results}

The regression analysis has been chosen to analyze the influence of parameters on flow on the performance criterion. The following connections between the studied parameters and factors have been suggested: a linear function with non-zero coefficient; linear function with zero coefficient; power function with non-zero coefficient; a power function with zero coefficient. The program Microsoft Excel has been used to build the model which has a built-in program to calculate regression. The regression analysis has been performed for each circuit using these functions. It is determined that linear function with non-zero coefficient will be the best for each scheme as $\mathrm{R}$-squared value is maximum and it is 0,999. Thus the regression models for the three schemes have been obtained.

The regression model for the $\ll$ Scheme $1 \gg$ :

$Y_{x}^{S c h 1}=-12590,89+1317,02 \cdot X_{1}+27,5 \cdot X_{2}$.

The regression model for the $\ll$ Scheme $2 \gg$ :

$$
Y_{x}^{S c h 2}=-22100+1428,5 \cdot X_{1}+44 \cdot X_{2} .
$$

The regression model for the $\ll$ Scheme $3 \gg$ :

$Y_{x}^{\text {Sch } 3}=-12982+1294,25 \cdot X_{1}+27,5 \cdot X_{2}$.

According to the received regression models, the cost determination was held. The input data at the maximum, average and minimum values of the parameters of the input stream of the orders were used, namely the volume of shipments and the distance of transportation. The results of calculation are presented in Table 3.

Table 3

The Results of Calculations of Efficiency Criterion

\begin{tabular}{|c|c|c|c|}
\hline \multirow{2}{*}{$\begin{array}{c}\text { Series of } \\
\text { experiments }\end{array}$} & \multicolumn{3}{|c|}{ Total cost on delivery [US\$] } \\
\cline { 2 - 4 } & «Scheme 1 & «Scheme 2» & «Scheme 3» \\
\hline 1 & 662 & 484 & 631 \\
\hline 2 & 1095 & 1177 & 1064 \\
\hline 3 & 1528 & 1869 & 1496 \\
\hline 4 & 5052 & 5246 & 4945 \\
\hline 5 & 5485 & 5938 & 5378 \\
\hline 6 & 5918 & 6631 & 5811 \\
\hline 7 & 9442 & 10007 & 9259 \\
\hline 8 & 9875 & 10700 & 9692 \\
\hline 9 & 10308 & 11393 & 10125 \\
\hline
\end{tabular}

The economic efficiency of the received model by comparing the total cost on delivery between the schemes is determined and the results are presented in the Table 4. 
Table 4

The Economic Effect on the Series of Experiments

\begin{tabular}{|c|c|c|c|}
\hline \multirow{2}{*}{$\begin{array}{c}\text { Series of } \\
\text { experiments }\end{array}$} & \multicolumn{3}{|c|}{ Economic effect [US\$ $]$} \\
\cline { 2 - 4 } & $\begin{array}{c}\text { Comparing «Scheme 1 } \\
\text { and «Scheme 2» }\end{array}$ & $\begin{array}{c}\text { Comparing «Scheme 1» } \\
\text { and «Scheme 3» }\end{array}$ & $\begin{array}{c}\text { Comparing «Scheme 2» } \\
\text { and «Scheme 3» }\end{array}$ \\
\hline 1 & 178 & 31 & -147 \\
\hline 2 & -82 & 31 & 113 \\
\hline 3 & -342 & 31 & 373 \\
\hline 4 & -194 & 107 & 301 \\
\hline 5 & -453 & 107 & 561 \\
\hline 6 & -713 & 107 & 820 \\
\hline 7 & -565 & 183 & 748 \\
\hline 8 & -825 & 183 & 1008 \\
\hline 9 & -1085 & 183 & 1268 \\
\hline
\end{tabular}

\section{Conclusion}

It is determined that in the current market conditions in the market of grain cargoes transportation in the containers, there is a perspective of their development, because every year the number of such orders in the address of transport companies is increasing. The scientific works have been analyzed in the sphere of organization of cargo delivery in the containers in which the authors focus on the development of multimodal transportation involving the rail, automobile and marine types of transport. Yet, it is specified that rail transport performs transportation in the conditions of critical depreciation of the main means and increasing competition from other types of transport (including automobile).

Three alternative technological schemes of delivery of grain cargoes in the international traffic have been proposed: the first scheme is with the use of the rail transport (grain cars) to deliver grain to the port of departure: «Car loading on the elevator - delivery to the port or the external terminal - reloading into the container - container delivery on the sea line - delivery to the end user $\gg$, the second scheme is with the use of road transport (bulk grain lorries) to deliver grain to the port of departure: «Loading of the bulk grain lorry on the elevator - delivery to the port or the external terminal - reloading into the container - container delivery by the sea line - delivery to the end user», the third scheme is with the use of the containers and wagons to deliver the grain to the port of departure: «Loading of the container on the elevator - the return of loaded containers in the port - reloading of the container with a cargo to the port or the external terminal - container delivery by sea line - delivery to the end user», moreover the third scheme has advantages such as minimal loss of cargo - up to $0.5 \%$ ».

The method of determination of the rational scheme of delivery of grain cargoes is proposed which allows after calculating the total cost to choose one of the three proposed schemes. The suppositions that have been proposed, take into account all the requirements of the customers, specifications of performing the operations by rail and road transport, as well as an organizational component of the use of the containers on transporting the grain cargoes. 
Based on the regression analysis of the results of the experiment, the regression model in the linear form with non-zero coefficient has been determined in which each coefficient indicates the degree of influence of the relative factor on the effective rate. It is determined that this model is the most appropriate, since indicator value $\mathrm{R}$-square is the largest and it equals 0,999 . The coefficients of regression model have also been tested that are appropriate according to the values of the standard deviation, t-statistics P-value, lower and upper coefficient. The results of the effect determination on the change of the distance of the cargo delivery for the volume of shipment of 200 tons have shown that «Figure 3» has got the greatest effect (the delivery using containers and wagons) at the distance of delivery $1000 \mathrm{~km}$.

It is planned to develop additional delivery schemes of grain cargoes in the containers in the international traffic, work out the elements of technology in details, define additional parameters of influence on the function and perform their statistical analysis.

\section{References}

Bowersox, D.J.; Closs, D.J.; Helferich, O.K. 1986. Logistical Management. New York: Macmillan Publishing Company. 586 p.

Boyson, S.; Corsi, T.M.; Dresner, M.E.; Harrington, L.H. 1999. Logistics and the Extended Enterprise: Benchmarks and Best Practices for the Manufacturing Professional. NY: John Willey and Sons. 230 p.

Chen, C.; Yan, W. 2012. Process analysis in container shipping network structure form change, International journal for traffic and transport engineering 2(1): 11-21.
Cherevychnyi Y. 2016. What problems appear at the record harvest of grain in Ukraine. Available from internet: <http://transport-journal.com/news/ kakye-problemyi-voznykayut-pry-rekordnom-urozhaezernovyih-v-ukrayne/>.

Collins, T.; Bell, M.; Bliemer, M. 2017. Urban intermodal terminals: The entropy maximising facility location problem, Transportation Research Part B: Methodological 100: 64-81.

Ellram, L.M.; Cooper, M.C. 1990. Supply Management, Partnership and the Shipper - Third Party Relationship, The International Journal of Logistics Management 1(2): 1-10.

Kozachenko D.M.; Rustamov R.S.; Matviyenko H.V. 2011. The directions to increase the efficiency of the transportation of grain cargoes by rail transport, EasternEuropean journal magazine of enterprise technologies: Collection of the scientific works 5/4(53): 20-22.

Naumov, V.; Shulika, O.; Velikodnyi, D. 2015. Results of experimental studies on choice of automobile intercity transport delivery schemes for packaged cargo, Motrol. Commission of Motorization and Energetics in Agriculture 17 (7): 87-91.

Pavlenko, O.; Potaman, N.; Kalinichenko, A.; Gontarenko, J. 2014. Evaluation of advisability of Transport-Logistic Center in the Transport Service Market, Information technology and management 2(20): 40-43.

Sayareh, J.; Iranshahi, S.; Golfakhrabadi, N. 2016. Service Quality Evaluation and Ranking of Container Terminal Operators, The Asian Journal of Shipping and Logistics 32(4): 203-212.

Schepler, X.; Balev, S.; Michel, S.; Sanlaville, E. 2017. Global planning in a multi-terminal and multi-modal maritime container port, Transportation Research Part E: Logistics and Transportation Review 100: 38-62. 
Song, D.P.; Dong, J.X. 2012. Cargo routing and empty container repositioning in multiple shipping service routes, Transportation Research Part B: Methodological 46(10): 1556-1575.

Velikodnyi, D. 2015. Study of selection of different options selection for technological preparation while transporting containers and packaged cargoes by road transport. In Proceedings of Contemporary Innovation Technique of the Engineering Personnel Training for the Mining and Transport Industry 2015 (CITEPTMTI'2015), 140-145.

Wisner, J.D.; Tan, K.C. 2000. Supply chain management and its impact on purchasing, Journal of Supply Chain Management 36(4): 33-42.
Zheng, X.B.; Park, N.K. 2016. A Study on the Efficiency of Container Terminals in Korea and China, The Asian Journal of Shipping and Logistics 32(4): 213-220.

Zhivitskaya, H. 2014. Topological Properties and Methodology of Research of Complex Logistic Systems Efficiency, ECONTECHMOD: an International Quarterly Journal on Economics of Technology, and Modelling Processes 3(3): 23-32. 